\title{
Determination and Speciation of Tellurium Hazardous Species in Real and Environmental Samples
}

\author{
Yousry M. Issa, Hussein M. Abdel-Fattah*, Ola R. Shehab, Nahla B. Abdel-Moniem \\ Chemistry Department, Faculty of Science, Cairo University, Giza, 12613, Egypt \\ *E-mail: dr_hussein5431@yahoo.com
}

doi: $10.20964 / 2016.09 .02$

Received: 11 May 2016 / Accepted: 29 June 2016 / Published: 7 August 2016

\begin{abstract}
Although tellurium is relatively rare in the environment, it is required in a number of important industrial applications such as semiconductor manufacturing, rubber industry, and solar panels. However, it has several environmental hazards and can be accumulated in the body and induce several health issues. It was reported that the toxicity of tellurium depends on its oxidation state with tellurite being the most toxic form. Determination and speciation of tellurite in real and environmental samples have been considered of primary analytical interest. Here, we have developed a simple technique for the analysis of tellurite in different chemical environments without the need for special pre-separation that is currently utilized in the standard quantitative techniques. This method depends on a carbon paste electrode modified with iron(II) phenanthrolin diclofenac $\left(\right.$ Fephen $\left.\mathrm{D}_{2}\right)$ and iron (II) bipyridyl diclofenac $\left(\right.$ FebipyD $\left._{2}\right)$ as electroactive phases in carbon paste. The sensors have the following features: low detection limit $\left(1.42 \times 10^{-5} \mathrm{~mol} / \mathrm{L}\right)$, long life time of more than 2 months, high selectivity to tellurite in the presence of a wide range of inorganic and organic ions, high thermal stability $\left(22-56{ }^{\circ} \mathrm{C}\right)$ and short response time of only 10-20 seconds. The sensors were successfully applied in the determination of tellurite in environmental and biological samples such as waste water, human serum, tellurite culture media, synthetic tellurite-cefotaxime and tellurite/tellurate mixtures. The results show high recovery rates, selective and highly reproducible response, indicating the suitability of the proposed sensors for practical applications.
\end{abstract}

Keywords: Tellurium, Carbon paste electrode, Environmental samples, Speciation analysis.

\section{$\underline{\text { FULL TEXT }}$}

(C) 2016 The Authors. Published by ESG (www.electrochemsci.org). This article is an open access article distributed under the terms and conditions of the Creative Commons Attribution license (http://creativecommons.org/licenses/by/4.0/). 